\title{
Enzalutamide/Goserelin Regimen
}

National Cancer Institute

\section{Source}

National Cancer Institute. Enzalutamide/Goserelin Regimen. NCI Thesaurus. Code

C160519.

A regimen consisting of enzalutamide and goserelin that can be used for the treatment of prostate cancer. 